frequencies. The switch at the listener's premises is naturally provided with a change-over position in which the receiver is connected to a suitable aerial for reception of other broadcast programmes in the usual manner.

Dr. Walmsley's paper described the technical development of the equipment which has resulted in this method being placed on a satisfactory and practical basis. The reading of the paper was accompanied by a demonstration of the reception of both normal broadcasting and of special programmes over the standard Post Office telephone lines, using both the audio and radio frequency methods described. In the latter case, the reception is unimpaired by the use of the subscriber's telephone for a call and conversation in the usual manner.

R. L. S-R.

\title{
RITUAL IN TIKOPIA OF THE SOLOMONS*
}

$\mathrm{I}^{\mathrm{N}}$ the first volume of his account of the ritual cycle known as "The Work of the Gods" in Tikopia, an isolated community in the British Solomon Islands Protectorate, Prof. Raymond Firth has confined himself mainly to giving an ethnographical account, reserving for later publication the major part of theoretical interpretation. In his introductory remarks, however, after pointing out that this, the most spectacular of his discoveries, had been mentioned only by the Rev. H. J. Durrad and Dr. H. R. Rivers without any hint that they were anything more than isolated performances, he goes on to indicate its basic significance for the understanding of Tikopia, while its analogies with rites in Hawaii and Tonga suggest interpretations of these latter, which cannot be inferred from the existing fragmentary and obscure accounts.

The rites fall into several main divisions: a symbolic set to initiate the cycle; a resacralization of canoes ; a reconsecration of temples; a series of harvest and planting rites for the rain; a sacred dance festival; several memorial rites and the rites of vanished temples; and in the trade wind season, the ritual manufacture of turmeric. The rites are one of the most elaborate expressions of the system of rank and of the religious beliefs of the people; it has important economic aspects, is related to the institution of marriage, sets the formal seal on fundamental forms of recreation, and provides sanctions for many of the most basic values.

The concrete title "The Work of the Gods" embodies two concepts : first that of a religious sanction, and secondly that of the ritual as a series of obligations involving the expenditure of goods and time. The religious sanction lies in the fact that the ritual cycle is believed to have been instituted primarily by one deity, the principal god of Kafika, who at the same time is worshipped by the chiefs of the other three clans; but into the scheme are drawn also other gods and chiefly ancestors. There is no elaborate mythology to explain how the ritual cycle came into sing. There is a strong reverence for the ritual and the sacred objects connected with it.

The important matter of fixing the exact day on which the rites shall begin throws a significant light on the calendrical system and astronomical knowledge of Tikopia. The people have no fixed calendar and no names for the months or for the days or nights of the month. They count moons or nights of the moon for specific purposes, as in estimating pregnancy or periods between events. The term tau, meaning a 'measurement' or 'count', is used for a

- The Work of the Gods in Tikopia. By Raymond Firth. (Published for the London School of Economics and Political Science.) Vol. 1. (Monographs on Social Anthropology, No. 1.) Pp. vi $+188+3$ plates. (London: Percy Lund, Humphries and Co., Ltd., 1940.) 78. 6d. season, or sometimes a year as a whole, but without precision. Sometimes a tau has six months, sometimes seven. It is a seasonal period rather than a calendar period and refers primarily to the most marked climatic phenomenon in the island, namely, the alternation of the trade wind with the monsoon season. The seasonal changes, which are accom. panied by changes in economic pursuits such as fishing, are the main basis for the seasonal ritual, as shown by the terms "The Work of the Trade Wind" and "The Work of the Monsoon". The trade wind begins to blow at about April and dies down in October, when the monsoon season begins.

Although the main index for the beginning is thus given by seasonal change, it is correlated with and corroborated by other factors. Though the Tikopia have no sidereal calendar, they use astronomical observation to a certain extent in time reckoning. Thus when the Pleiades rise, "the ocean has begun to bite", that is, the fish rise and are plentiful. It was said that when the Pleiades appeared above the sea in the east at dawn, it was the signal for the work of the trade wind to begin. At this time Taro, another star, stood high up at dawn. The work of the monsoon is also so guided. When Manu, a bright star, has passed the zenith in the evening, it is time to throw the firestick, for the season's work has arrived. Saraporu, another prominent star, stands midway in the western heavens in the evening at this time, but towards the end of the festival, when the dance festival begins, Saraporu has gone below the horizon. Tokens of the approach of the work of the monsoon season are also given by the migrations of birds and changes in vegetation.

The order of the rites of the Work of the Gods is traditionally fixed, though the space between them to some extent is at the discretion of the Ariki Kafika. But any ordinary Tikopia knows the sequence, and the full cycle in the traditional form shows that any man, not responsible for the organization of the rites, can carry in his memory a sequence of more than thirty days.

The Christianization of the Ariki Kafika, who took precedence over the other three chiefs in the rites, has brought about certain changes and adjustments. In the course of generations, such variation may become part of the traditionally accepted practice. This with the conseveration of other variations and causes of variation suggests the reflexion that "Polynesian cuiture must not be regarded as a static arrangement resting upon an original fusion of diverse elements, but as a dynamie arrangement with a tendency to variation perceptible in each genera. tion, and with a selective process by which some at least of these variations are built into the cultural system" 